\title{
Right bundle branch block masquerading as acute ST-segment elevation myocardial infarction
}

\author{
Wasawat Vutthikraivit MD, Sakolwan Suchartlikitwong MD
}

\section{CASE}

A 50-year-old man with a history of obstructive sleep apnea and morbid obesity presented with nausea and vomiting. He was found to have diabetic ketoacidosis (DKA) and acute pancreatitis. He did not report any chest pain but had epigastric pain. An electrocardiogram (ECG) demonstrated ST-segment elevation in leads II, III, and aVF with reciprocal changes in leads I and $\mathrm{QVL}$ and a complete right bundle branch block (RBBB). A cardiologist evaluated him for an acute inferior wall ST-segment elevation myocardial infarction. However, transthoracic echocardiogram showed normal left ventricular systolic function without regional wall motion abnormality, and exercise stress electrocardiography did not show evidence of myocardial ischemia. Since the patient's ECG showed typical findings of RBBB, the apparent ST-segment elevation in leads II, III, and aVF was considered to be part of QRS complex in RBBB (Figure 1). Likewise, the apparent reciprocal changes observed in leads I and $\mathrm{aVL}$ were also part of the QRS complex and not depression of the ST-segment (Figure 1). The patient's epigastric pain resolved after starting treatment for DKA and pancreatitis.

\section{Discussion}

The electrocardiogram has an important role in the diagnosis and the initial evaluation of patients with suspected acute coronary syndromes. ${ }^{1}$ An ST-segment elevation can occur in several cardiac abnormalities, including acute myocardial infarction, coronary vasospasm, pericarditis, left ventricular hypertrophy, Brugada syndrome, and fascicular bundle branch blocks. ${ }^{2}$ Right bundle branch block occurs when electrical activity of the heart, specifically the His-Purkinje system, is interrupted or altered, resulting in a widened QRS and ST-segment changes. ${ }^{3}$ The ECG findings of RBBB can sometimes lead to an over-interpretation of the ST-segment changes as acute myocardial infarction. Hence, it is important to know the difference between RBBB and ST-segment elevation myocardial infarction. Myocardial infarction always affects the left ventricle leading to impairment of the initial phase of ventricular depolarization, producing abnormal $Q$ waves. $^{4,5}$ In contrast, RBBB delays the terminal phase of ventricular depolarization, producing a wide R' wave in the right chest leads and a wide $S$ wave in the left chest leads but no abnormal $Q$ waves, as seen in our case (Figure 1). ${ }^{4,5}$

In conclusion, our case demonstrates a misreading of an inferior wall ST-segment elevation myocardial infarction in a patient with complete right bundle branch block. It is important for clinicians to know about other clinical presentations that could be misdiagnosed as acute coronary syndrome, since this misdiagnosis can lead to important complications.

Keywords: ECG, right bundle branch block, ST-segment elevation

Corresponding author: Wasawat Vutthikraivit Contact Information: Wv.vutthikravit@ttuhsc.edu6 DOI: $10.12746 /$ swrccc.v8i33.649 

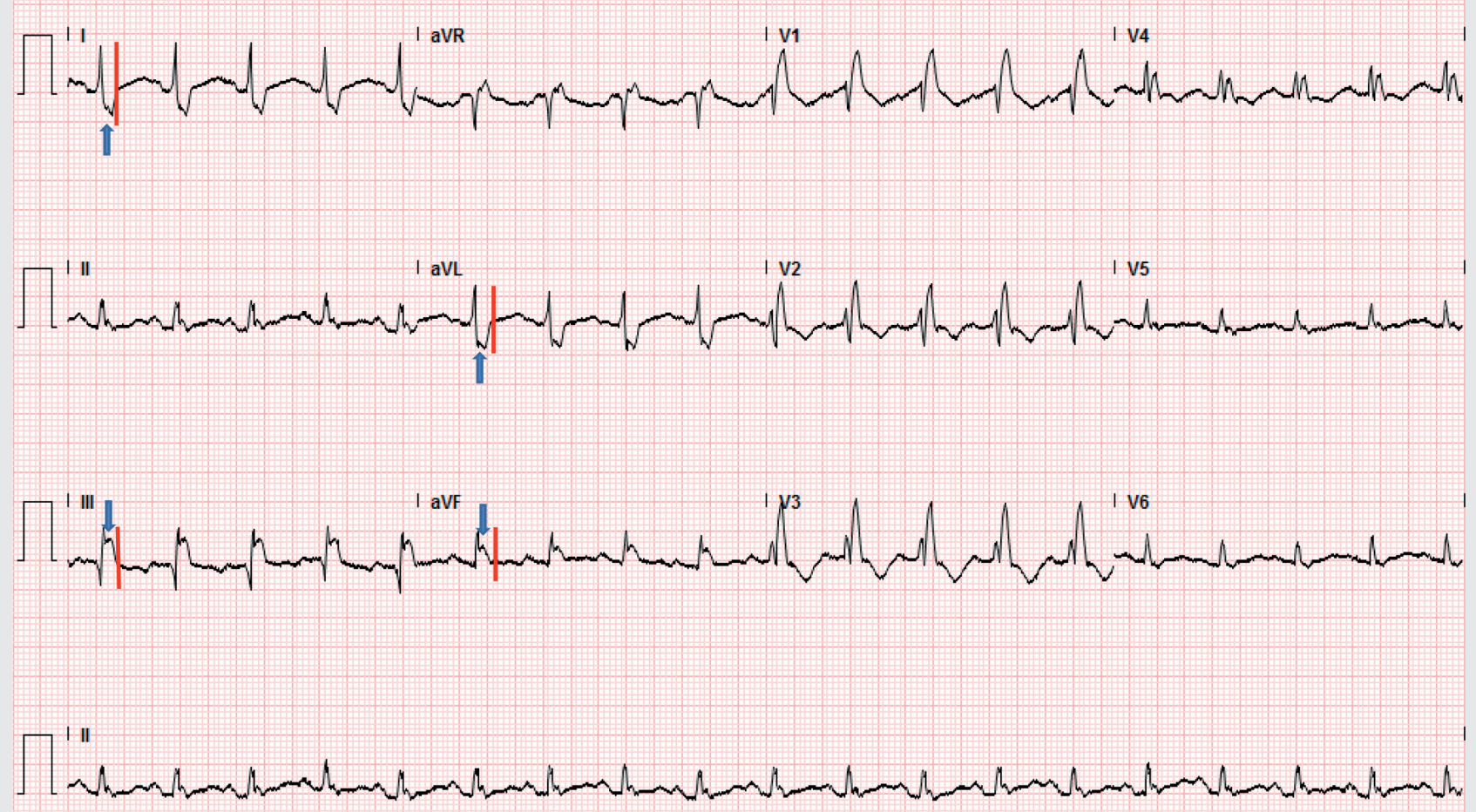

Figure 1. 12-lead Electrocardiogram (ECG) shows an elevation of ST segment at leads III, and aVF with the reciprocal change in leads I and aVL (arrows) with no Q waves in leads II and aVF. It also shows a typical finding of right bundle branch block (RBBB) with RSR' pattern at the right precordial leads (V1-V3). These ST segment elevations are part of QRS complex. There is no ST segment changes beyond the end of QRS complex (red lines).

Article citation: Vutthikraivit W, Suchartlikitwong S. Right bundle branch block masquerading as acute ST-segment elevation myocardial infarction. The Southwest Respiratory and Critical Care Chronicles 2020;8(33):72-73

From: Department of Internal Medicine, Texas Tech University Health Sciences Center, Lubbock, Texas

Submitted: $12 / 8 / 2019$

Accepted: $1 / 24 / 2020$

Reviewer: Deephak Swaminath MD

Conflicts of interest: none

This work is licensed under a Creative Commons

Attribution-ShareAlike 4.0 International License.

\section{REFERENCES}

1. Birnbaum Y, Drew BJ. The electrocardiogram in ST elevation acute myocardial infarction: correlation with coronary anatomy and prognosis. Postgraduate Med J 2003;79(935):490-504.

2. Coppola G, Carita P, Corrado E, et al. ST segment elevations: always a marker of acute myocardial infarction? Indian Heart J 2013;65(4):412-23.

3. Harkness WT, Hicks M. Right bundle branch block (RBBB). StatPearls. Treasure Island (FL) 2019.

4. Gussak I, Zhou SH, Rautaharju P, et al. Right bundle branch block as a cause of false-negative ECG classification of inferior myocardial infarction. J Electrocardiol 1999;32(3):279-84.

5. Gussak I, Wright RS, Bjerregaard P, et al. False-negative and false-positive ECG diagnoses of Q wave myocardial infarction in the presence of right bundle-branch block. Cardiology 2000;94(3):165-72. 